А.В. Калекина

\title{
ОСНОВНЫЕ НАПРАВЛЕНИЯ И ПОДХОДЫ К ИЗУЧЕНИЮ ПРОФЕССИОНАЛЬНОЙ КУЛЬТУРЫ ИНЖЕНЕРОВ-КОНСТРУКТОРОВ
}

\begin{abstract}
Аннотация. Статья посвящена рассмотрению основных направлений и подходов к изучению профессиональной культуры инженеров-конструкторов. Сущность профессиональной культуры инженеров-конструкторов рассматривается с позиций дисциплинарных и общеметодологических подходов, что создает предпосылки построения методологического конструкта, необходимого для исследования ее актуального состояния в современном российском обществе и понимания возможностей трансрормации в инновационный тип. Анализ существующих подходов делает обоснованным вывод о наличии теоретико-методологических проблем в интерпретации профессиональной культуры. В рамках каждого отдельного подхода профессиональная культура рассматривается в одной проекции, акцентирующей внимание на каких-либо отдельных ее аспектах, что приводит к различным определениям.

В работе рассматриваются следующие подходы к изучению профессиональной культуры: философский, культурологический, личностный, ценностно-ориентационный, сочиально-психологический, духовно-нравственный, профессионально-деятельностный, профессионально-стратификационный и другие. В связи с этим автором была предпринята попытка рассмотреть профессиональную культуру под разными углами зрения, выбирая их с учетом специфики профессиональной деятельности и объединяя в соответствии $c$ исследовательским замыслом. Основываясь на данных теоретико-методологических положениях, в соответствии с перечисленными признаками инженерной профессии, в статье уточнено понятие «профессиональная культура инженеров-конструкторов».

Выявленные подходы имеют принципиальное методологическое и мировоззренческое значение, задавая различные системы отсчета для понимания проблемы исследования профессиональной культуры инженеров-конструкторов.
\end{abstract}

Ключевые слова: психология, профессионализм, культура, инженеры-конструкторы, подходы к изучению, интерпретация, специфика, исследование, конструкт, трансформация.

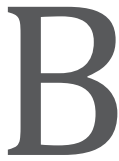

настоящее время, несмотря на провозглашаемую и никем не оспариваемую ценность высококультурного и разносторонне развитого профессионала, российские предприятия все еще ориентированы на узких специалистов, по сути придатков техники и технологии. Разрыв между уровнем востребованной производством квалификации и возможностями системы образования превращает последнюю в обслуживающий механизм производственного комплекса, что вступило в противоречие с дифференцированными образовательными запросами субъекта труда и обусловило отставание развития системы от мирового уровня подготовки специалистов.
Социальные ожидания в настоящий момент связаны с модернизацией профессионального образования, ориентацией на реализацию компетентностного подхода, индивидуализацию образовательных маршрутов, так как российские предприятия испытывают дефицит талантливых специалистов. Безусловно, создание сети образовательных учреждений и программ по профессиональному развитию субъектов труда - это прорыв в становлении профессионала нового типа. Однако недооценка проблемы формирования профессиональной культуры, адекватной времени, может свести на «нет» все усилия в этом направлении. 


\section{Профессиональная психология}

Профессиональная культура субъекта труда, хотя и является продуктом профессионального обучения, но не прямо вытекает из него, а является следствием саморазвития будущего специалиста на различных ступенях образования, причем не столько «технологического», сколько личностного роста, целостной самоорганизации культуры личности и культуры деятельности.

В научной литературе достаточно глубоко разработан общетеоретический фундамент изучения профессиональной культуры. Это обусловлено тем, что изучение профессиональной культуры носит во многом междисциплинарный характер, так как учитывает принадлежность психологов, социологов, философов, культурологов, экономистов к феномену, каковым является профессиональная культура.

Однако происходящие в социуме изменения темпа и вектора профессионального развития личности изменяют смысловые структуры сознания и социально-профессиональной позиции и переориентируют субъекта труда на новые цели. Принципиальные изменения условий, в которых осуществляется профессиональный путь субъекта труда, характеризуется существенным возрастанием роли профессиональной культуры. На практике это означает, что профессиональная культура субъекта труда в условиях инновационной трансформации нуждается в психологическом переосмыслении. Здесь необходимо констатировать наличие существенных теоретических проблем, которые пока не нашли своего разрешения в рамках психологии труда.

Переход к новой профессиональной культуре предполагает знание и понимание механизмов ее трансформации. В связи с этим представляет интерес рассмотрение сущности и содержания профессиональной культуры.

Особую актуальность и значимость приобретает проблематика психологического анализа профессиональной культуры инженеров-конструкторов, поскольку беспрецедентность осуществляемых трансформаций влечет за собой повышение эффективности адаптации субъектов труда к особенностям и требованиям современной инженерной деятельности.

Для теоретического обоснования сущности понятия «профессиональная культура инженеровконструкторов», а, следовательно, понимания закономерностей развития их профессионализма и повышения эффективности деятельности, необхо- дим анализ различных направлений и подходов к осмыслению данного феномена.

В настоящее время изучение профессиональной культуры ведется с позиции следующих подходов: философского, культурологического, личностного, ценностно-ориентационного, социально-психологического, духовно-нравственного, профессионально-деятельностного, профессионально-стратификационного, социально-экономического.

Сторонники одного из подходов характеризуют профессиональную культуру как систему ценностных ориентаций личности. Система ценностных ориентаций дана личности не как система знаний, а как система когнитивных образований, сопряженных с эмоционально - волевыми компонентами, принимаемая ею в качестве внутреннего ориентира, побуждающего и направляющего ее деятельность.

С.Г. Вергиловский выделил общие профессиональные ценности. К числу таких ценностей относятся: содержание профессиональной деятельности, обусловленные им возможности самореализации личности; общественная значимость труда, определяемая его результатом и последствиями; оценка трудовой деятельности человека в зависимости от степени её полезности для общества, оптимальный режим и условия труда. Данная классификация ценностей может быть применима к любой профессиональной деятельности, но она не отражает специфики, а, следовательно, и содержание профессиональной культуры работника ${ }^{1}$.

Следующий подход заключается в трактовке профессиональной культуры как личностного аспекта культуры труда. Автор данного подхода Г.Н. Соколова отмечает, что культура труда является мерой рациональности функционирования совокупного производственного процесса и его эффективности. Личностный аспект культуры труда в диалектической взаимосвязи с её объективной стороной, автором был рассмотрен как профессиональная культура работника. Такой подход обусловливает особенности анализа явления профессиональной культуры и представляет собой условие его функционирования и развития, а элементы профессиональной культуры, в свою очередь, интегрируются в систему культуры труда на фундаментальных и ценностных уровнях ${ }^{2}$.

\footnotetext{
1 Синергетика и психология. Тексты. Вып. 2: Социальные процессы. М.: ИП РАН, 2000. С. 120-132.

Соколова, Г.Н. Роль культуры в формировании личности / Г.Н. Соколова. М.: Наука, 1980. С. 89-110.
} 
Г.Н. Соколова считает, что показателем зрелости культуры труда является полнота реализации сил и способностей индивидов в процессе труда. Оценивать культуру труда в эмпирическом исследовании можно с помощью таких показателей как эффективность и качество работы, снижение трудоемкости, состояние здоровья человека. Однако главным показателем является степень реализации способностей человека в трудовой деятельности, осознание им труда как общественной ценности ${ }^{3}$.

В работах П.А. Сорокина профессиональная культура рассматривается через призму профессиональной стратификации, состоящей их двух видов: межпрофессиональной стратификации (иерархия основных профессий в любом типе общества) и внутрепрофессиональной стратификации (иерархия трех основных слоев внутри профессии - предприниматели, служащие высшей категории и наемные рабочие $)^{4}$. Основным критерием профессиональной стратификации автор выдвинул интеллектуальное содержание профессий и определил соответствующие им индексы интеллекта. Автор акцентирует свое внимание на профессиональной стратификации и профессиональной динамике, которые повышают профессиональную культуру.

В данном случае очевиден вывод о том, что с позиции психологии труда профессиональная культура не должна сводиться только к профессиональному образованию и мастерству, и не должна измеряться только интеллектом, так как профессиональная культура не существует в отдельно взятой профессии, а выражает общее культурное пространство.

Профессиональную культуру необходимо изучать в узком и широком смысле. В узком значении профессиональная культура - это совокупность специального образования, навыков, правил необходимых для четкого и квалифицированного выполнения профессиональных обязанностей. В широком значении профессиональная культура - это совокупность специальных знаний и неких нравственных принципов, которые выражают духовно-нравственные ценности бытия всего социума и, так или иначе, преломляются в профессиональной деятельности индивида.

А.И. Турчинов считает, что генезис общей профессиональной культуры носит во многом

\footnotetext{
3 Там же. С. 115-121.

4 Сорокин, П.А. Человек. Цивилизация. Общество / П.А. Сорокин. М.: Политиздат, 1992. С. 240-243.
}

личностный характер. Автор уточняет: «процесс профессионализации ... рассматривается и как состояние, как степень развитости способностей и профессиональных качеств человека, как процесс восхождения человека к вершинам профессионального развития...» ${ }^{5}$.

По мнению А.М. Омарова, профессиональная культура обеспечивает взаимоотношение людей, способ взаимных отношений человеческих контактов и носит название «социальное общение». Социальное и профессиональное общение отражает уровень культуры, все её достижения и недостатки ${ }^{6}$.

Л.Н. Коган отмечает, что культура профессиональной деятельности - овладение определенными знаниями, умениями, навыками для выполнения работ в той или иной отрасли. Он выделяет структурные элементы профессиональной культуры: «определенные знания, навыки, умения» для выполнения работы. Выделение культуры в таком аспекте необходимо на начальном этапе исследования профессиональной культуры и вытекает из самого его содержания ${ }^{7}$.

В монографии Н.Г. Багдасарьян профессиональная культура характеризуется нормами и стандартами, связанными с родом деятельности, а также принадлежностью индивида к определенной социально-профессиональной группе ${ }^{8}$. По нашему мнению, это достаточно упрощенное понимание профессиональной культуры, поскольку раскрывается в основном лишь технологический аспект («нормы и стандарты»).

Вышеприведенные трактовки профессиональной культуры, с нашей точки зрения, носят несистемный характер, включают разнородные признаки, которые определяются произвольно и из поля зрения выпадает либо технологический, либо психологический, либо социологический аспект. Это происходит, по нашему мнению, по причине ограниченности подходов, используе-

\footnotetext{
Турчинов, А.И. Профессионализм и кадровая политика: проблемы развития теории и практики / А.И. Турчинов. М.: Моск. психолого-социальный ин-т: Флинта, 1998. С. 132-137.

6 Омаров, А.М. Руководитель: размышления о стиле управления / А.М. Омаров. М.: Экономика, 1987. С. 117-132.

Коган, Л.М. Всестороннее развитие личности и социалистическая культура / Л.М. Коган. Екатеринбург: Ультра, 1992. C. 32-38.

8 Багдасарьян, Н.Г. Профессиональная культура инженера: механизмы освоения / Н.Г. Багдасарьян. М.: Изд-во МГТУ им. Н.Э. Баумана, 1998. С. 112.
} 


\section{Профессиональная психология}

мых авторами для трактовки профессиональной культуры. В связи с этим, необходимо анализировать данный феномен, каковым является профессиональная культура, начиная с родового понятия «культура».

В настоящее время насчитывается более двухсот определений культуры, отличающихся не только некоторыми деталями, но и существом понимания культуры. Важное значение при этом имеет учет философских и других научных позиций, с которых ученые рассматривают культуру. Стремление философии и психологии, на протяжении всех веков их существования, - выявить смысл мысленного преобразования всего видимого мира в мир человеческой культуры. Данный философский подход к культуре позволяет усмотреть в ней меру нашего собственного человеческого развития. Философия культуры есть философия самого человека, осознавшего себя в качестве единственного источника, цели и результата всего общественно исторического развития.

На сегодняшний день можно выделить следующие определения культуры.

Культура - явление историческое, развивающееся в зависимости от смены общественно-экономической формации. Признание того, что материальные отношения людей образуют основу всех их отношений, что определенная ступень развития производства, обмена и потребления обусловливает определенный общественный строй, служит основой научного объяснения развития человеческого общества и отношений между его экономической и культурной жизнью9.

По мнению ряда учёных, в том числе Э.В. Соколова, Н.С. Злобина, В.М. Межуева, культура должна рассматриваться в теснейшей связи с деятельностью людей ${ }^{10}$.

Таким образом, по нашему мнению, культура, с одной стороны, предстаёт как созданная в результате деятельности исторически конкретная и развивающаяся система ценностей, а с другой, - как особенность процесса, способ и мера реализации, совершенствования социальных (сущностных) сил человека.

\footnotetext{
9 Философский словарь / под ред. И.Т. Фролова. М.: Политиздат, 1986. С. 158-159.

10 См.: Соколов, Э.В. Культура и личность / Э.В. Соколов. Л.: Наука, 1972. С. 32; Злобин, Н.С. Культурные смыслы науки / Н.С. Злобин. М.: Олма-Пресс, 1997. С. 89; Межуев, В.М. Философия культуры / В.М. Межуев. М.: Прогресс, 2006. С. 28.
}

Пронизывая все сферы социальной жизни, культура в это же время является отдельным аспектом жизни общества. Культура - это социальное явление и, следовательно, вся социальная деятельность человека получает своё отражение в культуре.

Поэтому вполне естественно констатировать, что человек, овладевший профессией, профессиональными навыками, живёт и действует в условиях культуры. Человек, вступая во взаимодействие с культурой, усваивает культуру, начинает активно действовать в культурной среде и выступает как создатель культуры. Объективным критерием, показателем развития культуры в обществе служит степень той активности и универсальности, с какой человек относится к другим людям, к самому себе.

Следует отметить, что в большинстве работ современные авторы понимают культуру, главным образом, как воспроизводство самого человека, его знаний, представлений, отношений, навыков, материальных и духовных ценностей, как прогрессирующее само производство общественного человека, но при этом общие формулировки не позволяют выявить специфику профессиональной культуры.

В этом плане деятельностный подход, развиваемый в психологии труда, дает большие возможности исследования структуры профессиональной культуры, ее сущностных характеристик, позволяющих проводить операционализацию данного понятия.

Понятие деятельности является одним из основополагающих в психологии. В отечественной психологии категория деятельности является важнейшим из объяснительных принципов. Наиболее распространено следующее определение деятельности: «Деятельность - активное взаимодействие с окружающей действительностью, в ходе которого живое существо выступает как субъект, целенаправленно воздействующий на объект и удовлетворяющий таким образом свои потребности» ${ }^{11}$.

Центральным, системообразующим элементом любой деятельности является субъект, планирующий, осуществляющий, контролирующий, оценивающий деятельность. В ходе своей жизни индивид выступает субъектом множества деятельностей.

\footnotetext{
11 Асмолов, А.Г. Основные принципы психологической теории деятельности / А.Г. Асмолов // А.Н. Леонтьев и современная психология (Сб. статей памяти А.Н. Леонтьева) / под ред. А.В. Запорожца, В.П. Зинченко, О.В. Овчинниковой, О.К. Тихомирова. М.: Изд-во МГУ, 1983. С. 120.
} 
Важнейшей деятельностью социального субъекта является профессиональная деятельность, которой посвящена большая часть его жизни.

Е.А. Климов отмечает, что в современной психологии труда содержание деятельности, ее функциональная структура детерминирована заданным предметом и продуктом труда, культурно-исторически сложившимися орудиями, нормами, регламентирующими формами взаимодействия людей в труде, ответственностью, производственной (витальный, социальный, информационной) средой ${ }^{12}$.

Определяя деятельность как базовую категорию, отечественная психология рассматривает труд человека в качестве одного из основных видов деятельности наряду с игрой и учением в деятельностном подходе. Труд, игру, учение, созерцание - в субъектно-деятельностном подходе ${ }^{13}$.

Деятельность выступает одной из предпосылок и одновременно условием антропогенеза, онтогенеза, субъектогенеза. Она формирует и предопределяет появление и становление психики людей в целом и отдельного человека в процессе онтогенеза ${ }^{14}$.

Общепризнанной является концепция деятельности А.Н. Леонтьева, названная «теорией деятельности» — «деятельностным подходом» ${ }^{15}$.

В психологии труда именно деятельностный подход чаще всего выступает методологическим основанием для разработки более частных вопросов.

А.Н. Леонтьев рассматривает деятельность как систему (а не совокупность реакций), включенную в общественные отношения, как процесс, в котором происходит взаимный переход между полюсами «субъект-объект». Общественные условия жизни человека, по мнению А.Н. Леонтьева, задают мотивы и цели его деятельности, ее средства и способы, «общество производит деятельность образующих его индивидов». Основной ее характеристикой является предметность. Предметность деятельности обуславливает предметный характер образов, потребностей, эмоций и чувств человека ${ }^{16}$.

12 Климов, Е.А. Введение в психологию труда / Е.А. Климов. М.: Изд-во МГУ, 1988. С. 139.

13 Там же. С. 70.

14 Там же. С. 75-80.

15 Леонтьев, А.Н. Деятельность. Сознание. Личность / А.Н. Леонтьев. М.: Политиздат, 1977. С. 185.

16 Там же. С. 170-173.
Основным видом человеческой деятельности является труд, главные характеристики которого также признаются характеристиками предметной (профессиональной) деятельности.

Е.А. Климов предлагает отличать понятия «деятельность» в психологии от других форм активности, процессов. По мнению Е.А. Климова, под деятельностью необходимо понимать такую форму активности субъекта, которой присуще одновременно три базовых признака: 1) процесс действий (совокупность, последовательность неких актов); 2) процесс действий сознательно направлен на приспособление к требованиям среды и некоторое ее преобразование; 3) процесс действий имеет значение для существования и развития человека и общества ${ }^{17}$.

Е.М. Иванова, как и Е.А. Климов, рассматривает труд исключительно в контексте понятия «деятельность». «Основным видом деятельности человека является социально обусловленный, осознанный, целенаправленный труд, главные характеристики которого присущи и профессиональной (предметной) деятельности» ${ }^{18}$.

Следует также подчеркнуть, что в профессиональной деятельности происходит интеграция личного (личностного) и социального значений деятельности. При этом, имея ярко выраженный социальный характер, деятельность может считаться профессиональной только при соответствующем отношении к ней субъекта труда.

А.Н. Леонтьев, опираясь на идеи культурноисторической теории, выдвинул и детально разработал общепсихологическую концепцию деятельности. Деятельность в теории А.Н. Леонтьева рассматривается как философская категория. А.Н. Леонтьев отмечает, что она «входит в предмет психологии, но не особой своей «частью» или «элементом», а своей особой функцией. Это функция полагания субъекта в предметной действительности и ее преобразования в форму субъективности» ${ }^{19}$.

Психологический анализ деятельности, по мнению А.Н. Леонтьева, состоит «не в выделении из нее внутренних психических элементов для дальнейшего обособленного их изучения, а в том,

\footnotetext{
17 Климов, Е.А. Введение в психологию труда / Е.А. Климов. М.: Изд-во МГУ, 1988. С. 54.

18 Иванова, Е.М. Психология профессиональной деятельности / Е.М. Иванова, Е.А. Климов. М.: ПЕР СЭ, 2006. С. 112.

19 Леонтьев, А.Н. Деятельность. Сознание. Личность / А.Н. Леонтьев. М.: Политиздат, 1977. С. 170-171.
} 


\section{Профессиональная психология}

чтобы ввести такие единицы анализа, которые несут в себе психическое отражение в его неотторжимости от порождающих его и им опосредуемых моментов человеческой деятельности» ${ }^{20}$.

Основной характеристикой деятельности, в том числе и профессиональной, является ее предметность, научное исследование необходимо требует выявления специфики предмета каждой деятельности. «Предмет деятельности выступает двояко: первично - в своем независимом существовании как подчиняющий себе и преобразующий деятельность субъекта, вторично - как образ предмета, как продукт психического отражения его свойства, которое осуществляется в результате деятельности субъекта и иначе осуществляться не может» ${ }^{21}$.

Развернутые представления о деятельности как категории психологии содержатся в работе Б.Ф. Ломова. Согласно Б.Ф. Ломову, деятельность есть специфическая форма активности по преобразованию действительности, свойственная как человеку, так и обществу. Категория деятельности выявляет связь в системе «субъект - объект». «Именно в процессе деятельности осуществляется субъективное отражение объекта (предмета деятельности), а вместе с тем превращение этого объекта в ее продукт соответственно субъективной цели» ${ }^{22}$.

Б.Ф. Ломов указывает, что, как правило, в психологии деятельность индивида рассматривается как замкнутая система, подчиняющаяся своей внутренней логике, а жизнь человека как смена («поток») таких деятельностей. Однако «в действительности любая индивидуальная деятельность неразрывно связана с деятельностью общества, любой индивид - с другими людьми. Она представляет собой лишь момент, составную часть деятельности общества. Вне общественных связей и отношений индивидуальная деятельность просто не может существовать» ${ }^{23}$.

По мнению Б.Ф. Ломова, практически любая индивидуальная деятельность является частью совместной деятельности. Для совместной деятельности характерна регуляция индивидуальных действий с учетом действий, выполняемых другими участниками. Оценка результата в совместной

\footnotetext{
20 Там же. С. 160.

21 Там же. С. 179.

22 Ломов, Б.Ф. Методологические и теоретические проблемы психологии / Б.Ф. Ломов. М.: Наука, 1984. С. 190.

23 Там же. С. 193.
}

деятельности также обладает своей спецификой по сравнению с индивидуальной деятельностью: «во-первых, оценка осуществляется по критериям (и нормам), принятым в группе, во-вторых, сигнал обратной связи здесь относится не только к изменениям предмета, но и к оценке результата действий индивида со стороны других людей». По мнению автора, «важнейшими внутренними факторам совместной деятельности являются сотрудничество и соперничество. Они в значительной степени определяют ее эффективность» ${ }^{24}$.

Выполняя профессиональную деятельность, индивид реализует не одну социальную функцию, a их комплекс. Для профессиональной деятельности характерно включение субъекта в максимально широкую социально-культурную систему. Это влечет за собой социальные ожидания по отношению к субъекту труда, продукту труда, процессу деятельности ${ }^{25}$.

Анализ различных теоретических подходов к деятельности показал, что одной из основных характеристик деятельности является ее социальный характер. Особую значимость это положение приобретает в рамках профессиональной деятельности.

Профессиональная деятельность социально регламентирована, что выражается, главным образом, в нормативности труда. Нормы профессиональной деятельности всегда задаются социально, выполняют функцию внешнего контроля. В нормах находят выражение социальные ожидания по отношению к субъекту труда, продукту труда, процессу деятельности.

Применительно к профессиональной деятельности персонала предприятий главным аспектом рассмотрения будет личностный. Соответственно, профессиональная культура может быть представлена как культура личности субъекта труда - носителя определенных знаний, умений, навыков, способностей, традиций, норм деятельности.

Таким образом, исходя из подходов к пониманию деятельности, можно сделать вывод, что деятельность - материальная основа существования общества и важнейшая сфера проявления социальных (сущностных) сил и способностей человека. Профессиональная культура является одним из важных показателей, характеризующих трудовую деятельность субъекта труда с точки

\footnotetext{
24 Там же. С. 235-238.

25 Там же. С. 194-203.
} 
зрения ее психологической, социальной и экономической эффективности.

В содержательной плоскости профессиональная культура может быть определена как система смыслов и ценностей, порождаемых и формирующихся в процессе профессиональной подготовки и деятельности, а также в процессе исторического развития профессии.

В психологии труда феномен «профессия» выступает как теоретический объект, сущность которого можно отразить только посредством выделения совокупности признаков, каждый из которых является обобщенным понятием.

Е.А. Климов выделил следующие значения употребления понятия «профессия» ${ }^{26}$ :

- $\quad$ область приложение сил человека (как субъекта труда);

- общность людей-профессионалов;

- подготовленность человека, позволяющая выполнять определенную работу;

- деятельность, сам процесс реализации трудовых функций.

Позднее Е.А. Климов выделяет более конкретные аспекты понятия «профессия»: профессия как общность людей, занимающихся близкими проблемами и ведущих примерно одинаковый образ жизни, которая накладывает свой отпечаток на всю жизнь человека; профессия как область приложения сил; профессия как деятельность и область проявления личности; профессия как исторически развивающаяся система; профессия как реальность, творчески формируемая самим субъектом труда. В конкретных аспектах данного понятия Е.А. Климов феномен профессии рассматривает в «основных значениях» социальных отношений.

Н.С. Пряжников выделяет основные характеристики профессии, такие как: ограниченный вид трудовой деятельности (вследствие исторического разделения труда); общественно полезная деятельность, предполагающая специальную подготовку, выполняемая за определенное вознаграждение моральное и материальное, «дающее человеку возможность удовлетворять свои насущные потребности, выступающее необходимым условием его всестороннего развития»; деятельность, делающая человеку определенный и общественный статус (во многом формирующая Я-концепцию множеством «составляющих» профессии: долж-

26 Климов, Е.А. Введение в психологию труда / Е.А. Климов. М.: Изд-во МГУ, 1988. С. 107. ность, стаж, квалификация, высшие профессиональные достижения и т.д.); отношение к данной работе как к своей профессии, как «главная психологическая характеристика» ${ }^{27}$.

Э.Ф. Зеер выделяет следующие «отличительные признаки» профессии: профессиональная компетентность, профессиональная автономия, групповые нормы и ценности, самоконтроль ${ }^{28}$.

А.К. Маркова, рассматривая феномен профессии, выделяет следующие аспекты:

- профессии как исторически возникающие и социально востребованные формы деятельности, «для выявления которых человек должен обладать суммой знаний и навыков, иметь соответствующие способности»;

- профессия «с точки зрения общества» - «социально зафиксированная область осуществления трудовых функций, система профессиональных задач, форм и видов деятельности, особенностей личности»;

- $\quad$ профессия «с точки зрения конкретной личности» - «деятельность, посредством которой человек участвует в жизни общества и которая служит ему источником материальных средств к существованию» ${ }^{29}$.

Каждая профессия имеет свой характерный «жаргон», кодекс поведения, тип мышления, определяющий стиль жизни ее представителей. По мнению Р. Ходсон и Т. Саливан, перечисленные характеристики являются элементами профессиональной культуры, они определяют профессиональную культуру как субкультуру внутри национальной культуры и отмечают, что профессиональные школы дают не только знания, но и прививают нормы, ценности и жизненный стиль, характерные для какой-либо профессии ${ }^{30}$.

Исходя из вышеизложенного, можно сделать вывод о том, что профессия дает ее носителю определенные социальные преимущества и опре-

27 Пряжников, Н.С. Психологический смысл труда / Н.С. Пряжников. М.: Изд-во Ин-та практич. психологии; Воронеж: НПО «МОДЭК», 1997. С. 189-192.

28 Зеер, Э.Ф. Психология профессий / Э.Ф. Зеер. Екатеринбург: УГППУ, 1997. С. 52.

29 Маркова, А.К. Психология профессионализма / А.К. Маркова. М.: Междунар. гуманитарный фонд «Знание», 1996. C. 39-142.

30 Sullivan, T.A. The social organization of work / T.A. Sullivan, R. Hodson. Belmont, CA: Wadsworth/Thomson Learning, 2002. P. 110. 


\section{Профессиональная психология}

деленную власть, а профессиональная подсистема социально дифференцирована и внутренне конфликтна.

Профессионализм соизмерим с творческим отношением к делу. Профессионал непрерывно рождается внутри самой работы, на каждом ее этапе. Профессионал - это человек, который должен соответствовать требованиям профессиональной деятельности, уметь высвобождаться из-под власти стереотипов и порождать совершенно новый, предельно точный продукт труда. Деятельность профессионала всегда имеет личностный оттенок, в ней отражается и воплощается его личность.

Е.А. Климов отмечает, что «Профессиональная культура не отделима от ее «носителя» человека, поэтому система учебных дисциплин должна быть ориентирована на формирование определенного склада личности профессионала, характеризующегося единством типичных индивидуальных особенностей, профессиональной направленностью, особыми чертами характера, ума, чувств» ${ }^{31}$. Он отмечает, что профессиональная жизнь современного человека - динамичная, насыщенная, постоянно обновляющаяся - ставит перед нами новые и интересные задачи, которые сегодня определяют перспективы развития психологии в целом ${ }^{32}$.

Е.А. Климов, анализируя структуру профессионального самосознания, выделяет тот аспект «Я-образа», в котором сосредоточены представления о своих профессионально-ценностных качествах, способностях, темпераменте, характере, интересах, потребностях и убеждениях, о себе в прошлом, настоящем и будущем внутри профессии ${ }^{33}$.

Рассмотренные подходы к пониманию профессий и профессионалов подчеркивают органическое переплетение единства процессов профессиональной деятельности и жизни. Изучаемые феномены порождают стремления осмыслить природу различных парадигм и подходов, выстроить своеобразную ретроспективу и перспективу исследования профессиональной культуры.

В обыденном сознании, в том числе в сознании профессионалов, профессиональная культура

\footnotetext{
31 Климов, Е.А. Психология профессионала / Е.А. Климов. М.: Изд-во «Институт практической психологии»; Воронеж: НПО «МОДЭК», 1996. С. 148.

32 Там же. С. 53.

33 Климов, Е.А. Введение в психологию труда / Е.А. Климов. М.: Изд-во МГУ, 1988. С. 40-45.
}

- это оценочная категория и категория достижения. Она может отсутствовать у людей, получивших специальную подготовку и, наоборот, присутствовать у талантливых дилетантов. Психология профессионала является своеобразной средой, которая порождает феномены профессиональной культуры.

Если принять во внимание особенности инженерной профессии, то определение профессиональной культуры приобретает вполне конкретную специфику. В современном массовом представлении понятие инженер многозначно - это создатель новой техники и технологии, проектировщик, исследователь, технолог, дизайнер, организатор производства.

Инженерная профессия определяется следующими признаками:

- принадлежность к практической деятельности, к материальному производству;

- $\quad$ направленность на создание техники, которая представляет предмет деятельности инженера;

- $\quad$ творческий характер, с выделением научно технического творчества, целью которого является новое знание, и собственно инженерного творчества, результатом которого является новая техника или технология;

- системный характер, многомерность, связанная с учетом всего многообразия факторов практической деятельности, с определением противоречий между целями и средствами ${ }^{34}$.

Следовательно, идеальная модель инженерной профессиональной деятельности в современной ситуации включает в себя не только технико-технологические факторы, в их определенном сочетании, но и психологические, и социокультурные факторы использования техники и технологии в обществе.

Профессиональная культура инженера любой специализации включает в себя профессиональные знания, умения, навыки, профессиональный опыт, который во многом помогает применению наиболее рациональных приемов обеспечения эффективности деятельности и ее результатов. Инженер должен уметь нечто такое, что нельзя охарактеризовать словом «знает», он должен обладать инженерным типом мышления.

Основываясь на данных теоретико-методологических положениях, в соответствии с

34 Соколов, Э.В. Культура и личность / Э.В. Соколов. Л.: Наука, 1972. С. 57. 
перечисленными признаками инженерной профессии, профессиональная культура инженеровконструкторов - это динамическое сложное явление, мера и качество креативизации деятельности, представляющее собой совокупность знаний, умений, навыков, ценностей личности, морально-этических установок, встраиваемое в общий ход психического развития субъекта труда и обеспечивающее его профессиональное развитие и совершенствование.

Следовательно, в рамках излагаемых направлений и подходов, профессиональная культура инженеров-конструкторов должна определяться не только как совокупность групповых норм профессиональной общности и как способ деятель- ности профессионала, обладающего своим индивидуальным типом мышления, формируемым в процессе групповой коллективной деятельности, но и как результат интегративного процесса взаимодействия субъекта труда и трудовой среды, имеющий высокую значимость в рамках психологического развития личности профессионала и, как следствие, повышения результативности его деятельности.

Системный анализ профессиональной культуры инженеров-конструкторов дает возможность определить психологическую концепцию ее исследования и выявить тенденции и перспективы развития этого феномена для современной психологии труда.

\section{Список литературы:}

1. Асмолов, А.Г. Основные принципы психологической теории деятельности / А.Г. Асмолов // А.Н. Леонтьев и современная психология (Сб. статей памяти А.Н. Леонтьева) / под ред. А.В. Запорожца, В.П. Зинченко, О.В. Овчинниковой, О.К. Тихомирова. М.: Изд-во МГУ, 1983. С. 118-128.

2. Багдасарьян, Н.Г. Профессиональная культура инженера: механизмы освоения / Н.Г. Багдасарьян. М.: Изд-во МГТУ им. Н.Э. Баумана, 1998. 150 с.

3. Зеер, Э.Ф. Психология профессий / Э.Ф. Зеер. Екатеринбург: УГППУ, 1997. 244 с.

4. Злобин, Н.С. Культурные смыслы науки / Н.С. Злобин. М.: Олма-Пресс, 1997. 287 с.

5. Иванова, Е.М. Психология профессиональной деятельности / Е.М. Иванова, Е.А. Климов. М.: ПЕР СЭ, 2006. 178 c.

6. Климов, Е.А. Психология профессионала / Е.А. Климов. М.: Изд-во «Институт практической психологии»; Воронеж: НПО «МОДЭК», 1996. 387 с.

7. Климов, Е.А. Введение в психологию труда / Е.А. Климов. М.: Изд-во МГУ, 1988. 199 с.

8. Коган, Л.М. Всестороннее развитие личности и социалистическая культура / Л.М. Коган. Екатеринбург: Ультра, 1992. 320 с.

9. Леонтьев, А.Н. Деятельность. Сознание. Личность / А.Н. Леонтьев. М.: Политиздат, 1977.304 с.

10. Ломов, Б.Ф. Методологические и теоретические проблемы психологии / Б.Ф. Ломов. М.: Наука, 1984. $444 \mathrm{c}$.

11. Маркова, А.К. Психология профессионализма / А.К. Маркова. М.: Междунар. гуманитарный фонд «Знание», 1996. 310 с.

12. Межуев, В.М. Философия культуры / В.М. Межуев. М.: Прогресс, 2006. 345 с.

13. Омаров, А.М. Руководитель: размышления о стиле управления / А.М. Омаров. М.: Экономика, 1987. 295 c.

14. Пряжников, Н.С. Психологический смысл труда / Н.С. Пряжников. М.: Изд-во Ин-та практич. психологии; Воронеж: НПО «МОДЭК», 1997. 352 с.

15. Синергетика и психология. Тексты. Вып. 2: Социальные процессы. М.: ИП РАН, 2000. 159 с.

16. Соколова, Г.Н. Роль культуры в формировании личности / Г.Н. Соколова. М.: Наука, 1980.216 с.

17. Соколов, Э.В. Культура и личность / Э.В. Соколов. Л.: Наука, 1972. 411 с.

18. Сорокин, П.А. Человек. Цивилизация. Общество / П.А. Сорокин. М.: Политиздат, 1992.543 с.

19. Турчинов, А.И. Профессионализм и кадровая политика: проблемы развития теории и практики / А.И. Турчинов. М.: Моск. психолого-социальный ин-т: Флинта, 1998. 317 с.

20. Философский словарь / под ред. И.Т. Фролова. М.: Политиздат, 1986. 590 с.

21. Sullivan, T.A. The social organization of work / T.A. Sullivan, R. Hodson. Belmont, CA: Wadsworth/Thomson Learning, 2002. 480 p. 


\section{Профессиональная психология}

\section{References (transliteration):}

1. Asmolov, A.G. Osnovnye printsipy psikhologicheskoi teorii deyatel'nosti / A.G. Asmolov // A.N. Leont'ev i sovremennaya psikhologiya (Sb. statei pamyati A.N. Leont'eva) / pod red. A.V. Zaporozhtsa, V.P. Zinchenko, O.V. Ovchinnikovoi, O.K. Tikhomirova. M.: Izd-vo MGU, 1983. S. 118-128.

2. Bagdasar'yan, N.G. Professional'naya kul'tura inzhenera: mekhanizmy osvoeniya / N.G. Bagdasar'yan. M.: Izdvo MGTU im. N.E. Baumana, 1998. 150 s.

3. Zeer, E.F. Psikhologiya professii / E.F. Zeer. Ekaterinburg: UGPPU, 1997. 244 s.

4. Zlobin, N.S. Kul'turnye smysly nauki / N.S. Zlobin. M.: Olma-Press, 1997. 287 s.

5. Ivanova, E.M. Psikhologiya professional'noi deyatel'nosti / E.M. Ivanova, E.A. Klimov. M.: PER SE, 2006. 178 s.

6. Klimov, E.A. Psikhologiya professionala / E.A. Klimov. M.: Izd-vo «Institut prakticheskoi psikhologii»; Voronezh: NPO «MODEK», 1996. 387 s.

7. Klimov, E.A. Vvedenie v psikhologiyu truda / E.A. Klimov. M.: Izd-vo MGU, 1988. 199 s.

8. Kogan, L.M. Vsestoronnee razvitie lichnosti i sotsialisticheskaya kul'tura / L.M. Kogan. Ekaterinburg: Ul'tra, 1992. $320 \mathrm{~s}$.

9. Leont'ev, A.N. Deyatel'nost'. Soznanie. Lichnost' / A.N. Leont'ev. M.: Politizdat, 1977. 304 s.

10. Lomov, B.F. Metodologicheskie i teoreticheskie problemy psikhologii / B.F. Lomov. M.: Nauka, 1984. $444 \mathrm{~s}$.

11. Markova, A.K. Psikhologiya professionalizma / A.K. Markova. M.: Mezhdunar. gumanitarnyi fond «Znanie», 1996. $310 \mathrm{~s}$.

12. Mezhuev, V.M. Filosofiya kul'tury / V.M. Mezhuev. M.: Progress, 2006. 345 s.

13. Omarov, A.M. Rukovoditel': razmyshleniya o stile upravleniya / A.M. Omarov. M.: Ekonomika, 1987. 295 s.

14. Pryazhnikov, N.S. Psikhologicheskii smysl truda / N.S. Pryazhnikov. M.: Izd-vo In-ta praktich. psikhologii; Voronezh: NPO «MODEK», 1997.352 s.

15. Sinergetika i psikhologiya. Teksty. Vyp. 2: Sotsial'nye protsessy. M.: IP RAN, 2000. 159 s.

16. Sokolova, G.N. Rol' kul'tury v formirovanii lichnosti / G.N. Sokolova. M.: Nauka, 1980. 216 s.

17. Sokolov, E.V. Kul'tura i lichnost' / E.V. Sokolov. L.: Nauka, 1972. 411 s.

18. Sorokin, P.A. Chelovek. Tsivilizatsiya. Obshchestvo / P.A. Sorokin. M.: Politizdat, 1992. 543 s.

19. Turchinov, A.I. Professionalizm i kadrovaya politika: problemy razvitiya teorii i praktiki / A.I. Turchinov. M.: Mosk. psikhologo-sotsial'nyi in-t: Flinta, 1998. $317 \mathrm{~s}$.

20. Filosofskii slovar' / pod red. I.T. Frolova. M.: Politizdat, 1986. 590 s.

21. Sullivan, T.A. The social organization of work / T.A. Sullivan, R. Hodson. Belmont, CA: Wadsworth/Thomson Learning, 2002. $480 \mathrm{p}$. 